\title{
Can patient and fracture factors predict opioid dependence following upper extremity fractures?: a retrospective review
}

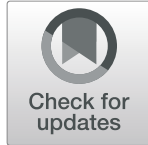

Vani Janaki Sabesan ${ }^{1 *} \mathbb{D}$, Kiran Chatha ${ }^{1}$, Lucas Goss², Claudia Ghisa ${ }^{2}$ and Gregory Gilot ${ }^{1}$

\begin{abstract}
Background: Since the early 1990s, opioids have been used as a mainstay for pain management surrounding fracture injuries. As opioid dependence has become a major public health issue, it is important to understand what factors can leave patients vulnerable. The purpose of this study was to examine what risk factors, patient or injury severity, contribute most to postoperative opioid dependence following surgical treatment of proximal humerus fractures (PHFs).
\end{abstract}

Methods: A retrospective review of all patients who underwent an open reduction and internal fixation of PHF was performed within a large multisite hospital system. Recorded variables included age, gender, ASA class, BMl, fracture type, time to surgery, pre- and postoperative opioid prescriptions, physical and psychological comorbidities, smoking status, and complications. Pre- and postoperative opioid dependence was defined as prescription opioid use in the 3 months leading up to or following surgery. Odds ratio calculations were performed for each variable, and a multivariate logistic regression was used to compare all predictors.

Results: A total of 198 surgically treated PHFs were included in the cohort with an average age of 59.9 years. Thirty-nine cases were determined to be preoperatively opioid dependent while 159 cases were preoperatively opioid naïve. Preoperative opioid dependence was found to be a significant risk factor for postoperative narcotic dependence, carrying a 2.42 times increased risk. (Cl 1.07-5.48, $p=0.034$ ). Fracture type was also found to be a risk factor for postoperative dependence, with complex 3- and 4-part fracture patients being 1.93 times more likely to be opioid dependent postoperatively compared to 2 part fractures $(\mathrm{Cl} 1.010-3.764, p=0.049)$. All other factors were not found to have any significant influence on postoperative opioid dependence.

Conclusions: Our results demonstrate that the most important risk factors of postoperative opioid dependence following proximal humerus fractures are preoperative dependence and fracture complexity. It is important for orthopedic surgeons to ensure that patients who have more complex fractures or are preoperatively opioid dependent receive adequate education on their increased risk and support to wean off of opioids following surgery.

Level of evidence: III

Keywords: Opioid dependence, Proximal humerus fracture, Predictors for opioid dependence, Patient factors

\footnotetext{
*Correspondence: Sabes001@gmail.com; sabes001@gmail.com

This study was approved by the Cleveland Clinic Florida IRB. (IRB \#)

'Levitetz Department of Orthopedic Surgery, Cleveland Clinic Florida, 2950

Cleveland Clinic Blvd, Weston, FL 33132, USA

Full list of author information is available at the end of the article
}

(c) The Author(s). 2019 Open Access This article is distributed under the terms of the Creative Commons Attribution 4.0 International License (http://creativecommons.org/licenses/by/4.0/), which permits unrestricted use, distribution, and reproduction in any medium, provided you give appropriate credit to the original author(s) and the source, provide a link to the Creative Commons license, and indicate if changes were made. The Creative Commons Public Domain Dedication waiver (http://creativecommons.org/publicdomain/zero/1.0/) applies to the data made available in this article, unless otherwise stated. 


\section{Background}

Currently, approximately 115 Americans die every day from an opioid overdose [1]. Over the last two decades, the number of prescribed opioids, as well as the number of deaths from opioids has increased five-fold [1]. Orthopedic surgeons are the third highest prescribers of opioids in the USA and the highest when compared to other surgical subspecialties [2]. Because orthopedic trauma and related procedures can be extremely painful, patients have often been prescribed excessive opioidbased medications following treatment as no particular guidelines existed until recent legal and regulatory changes have been implemented [3, 4]. Humeral fractures can be very painful and most commonly, pain from this type of fracture and subsequent surgery is managed with opiate-based medications.

It has been well established that preoperative opioid use has been associated with an increased risk of opioid dependence, decreased clinical outcomes and lower patient satisfaction in those undergoing orthopedic surgery [5-14]. Specifically, for orthopedic trauma patients research has found that prolonged postoperative opioid use adversely affects patient-reported outcomes and satisfaction $[15,16]$. In addition to preoperative opioid use, other risk factors for increased risk of opioid abuse that have been reported include psychopathology, history of substance abuse, chronic pain, and family history of alcohol and substance abuse [17]. In other fields, screening tools have been developed to aid in recognizing patients that may be at higher risk for opioid abuse, but these are lacking in orthopedic trauma patients [18]. A surgeon's pre-treatment understanding of risk factors for potential opioid misuse is essential to mitigating the problems associated with these medications.

It is unknown whether type of fracture alone is a risk factor, but orthopedic trauma patients have been shown to experience post-traumatic stress syndrome, depression, and anxiety, which are all associated with increased risk for opioid misuse, among other substances [17, 19, 20]. Rosenbloom et al. recently reported $35 \%$ rate of opioid usage 4 months after surgery for orthopedic trauma patients which was significantly higher than non-trauma associated postsurgical patients $(0.4-3.1 \%)$ [4, 21]. Recent literature examining fracture morphology in animal models has also suggested that higher pain is experienced with more bone marrow exposure [22]. The purpose of this study was to examine specific risk factors including patient characteristics and fracture morphology that may influence postoperative opioid dependence in patients undergoing ORIF for proximal humerus fractures. We hypothesized that preoperative opioid consumption would be the strongest predictor of postoperative opioid dependence as this is well established in the literature (Fig. 1).

\section{Methods}

A retrospective review of patients who underwent open reduction internal fixation of proximal humerus fractures (PHF) was performed from 2012 to 2016 in a multisite hospital system. Patients were identified using CPT code 23615 (proximal humerus fracture open reduction and internal fixation (ORIF)). Demographic data collected included age, gender, ASA class, BMI, fracture type, smoking status, psychological, and physical comorbidities. Fractures were

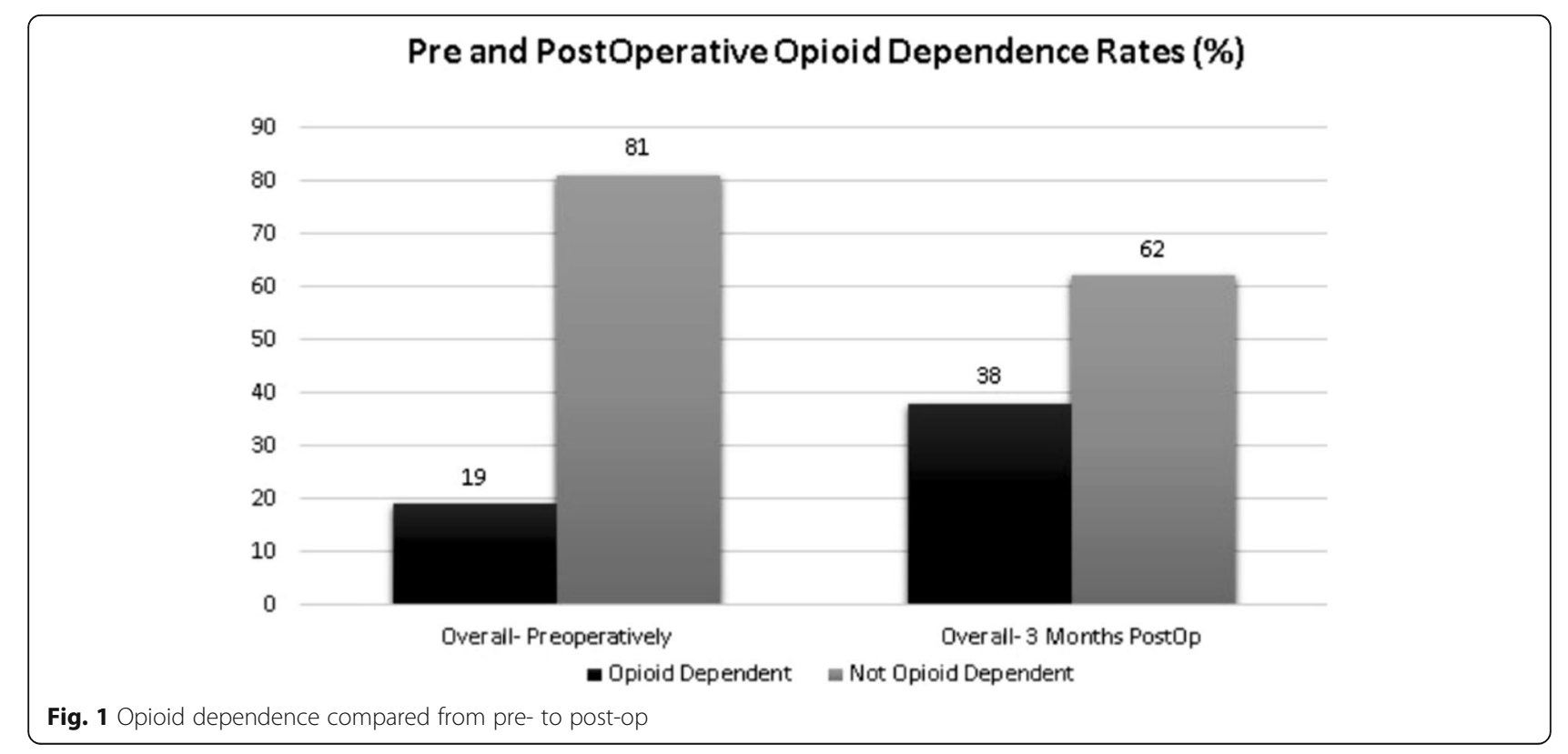


classified based on the Neer classification system, and the analysis was performed comparing the 2-part fracture (Simple) group to the 3- and 4-part (complex) fracture group [23]. Patients were categorized based on ASA class (group $1=$ class 1 and 2 and group $2=$ class 3 and 4) and obesity was defined as a BMI greater than 30. Smoking status was divided based on patients who had a history of smoking and patients who never smoked. Psychological comorbidities were defined as any recorded diagnosis that would be included in the DSM-V [24]. Number of follow-up visits and the amount of time between injury and surgery was also recorded in days.

Opioid prescriptions were recorded for 6 months prior to and 1 year following surgery. All opioid prescriptions were verified using state prescription drug monitoring websites $[25,26]$. For each prescription, the medication, dosage, number of pills, and prescribed total morphine equivalents were collected. For patients with multiple opioid prescriptions, an average prescribed total morphine equivalent was calculated. Preoperative and postoperative opioid dependence was defined as continued prescriptions for at least 3 months prior to or following surgery. Total morphine equivalents were compared and analyzed between the preand postoperative groups at each time interval.

Descriptive statistics reported the effect of each demographic variable on narcotic dependence. Statistical analyses then compared preoperatively dependent and naïve cohorts using $t$ tests and chi-square test for dependence rates and TMEs prescribed. A multivariate logistic regression was performed to identify significant risk factors and calculate postoperative odds ratios for relative risk of dependence associated with each factor. The primary outcome variable of the model was postoperative opioid dependence. A subanalysis of opioid-dependent patients' prescription TMEs and dependence rates was performed. All statistical analyses were performed using SPSS Software (IBM, Version 23).

\section{Results}

A total of 159 PHFs patients were included in the cohort, with an average age of the 59.9 years and 115 females and 44 males included. Thirty-nine cases were determined to be preoperatively opioid dependent (group 1) while 120 cases were preoperatively opioid naïve (group 2) with no recorded opioid prescriptions in the 6 months leading to surgery. A total of 74 patients were postoperatively dependent on opioids at 3 months. There were no significant differences in age, ASA class, BMI, or psychological comorbidities between the two groups (Table 1). At 30 days postoperatively, $55 \%$ of the opioid naïve cohort was able to wean off of opioids while $74 \%$ of the preoperatively opioid dependent cohort remained on opioids.

Preoperative opioid dependence was found to be a statistically significant risk factor for postoperative opioid dependence, carrying a 2.42 times increased risk. (CI $1.07-5.48, p=0.034$ ). Of the preoperatively naïve group, fracture type was also found to be a risk factor for postoperative dependence, with complex 3- and 4-part fracture patients being 1.93 times more likely to be opioid-dependent postoperatively compared to 2-part fractures (CI 1.01-3.76, $p=0.049$ ). There was no influence on postoperative opioid dependence for all other factors in the model including smoking status, ASA class, BMI, or comorbidity burden (Table 2).

Those patients that were preoperatively dependent required significantly higher (1.2 times) total morphine equivalents postoperatively $(p=0.04)$. Preoperatively dependent patients received prescriptions from their orthopedic surgeon for a significantly longer period of time, for an average of 80 days following surgery compared to the narcotic naïve cohort who received narcotic prescriptions for an average of 53 days $(p=0.03)$.

\section{Discussion}

Our results demonstrate that the strongest risk factor for postoperative opioid dependence following a proximal humerus fracture is preoperative opioid dependence which is

Table 1 Comparison of patient demographics in opioid-dependent and naive groups

\begin{tabular}{llll}
\hline Demographics & Opioid dependent $n=39$ & Opioid non-dependent $n=120$ & $p$ value \\
\hline Female gender & $28(72 \%)$ & $87(72.5 \%)$ & 0.931 \\
Psychological comorbidity & $20(51 \%)$ & $39(32 \%)$ & $0.034^{*}$ \\
Simple fractures & $22(56 \%)$ & $72(60 \%)$ & 0.691 \\
Mean comparisons between groups & & & 0.292 \\
Age & 59.8 & 59.2 & 0.093 \\
ASA class & 2.64 & 2.44 & 0.14 \\
BMl & 29.82 & 27.39 & 0.953 \\
Procedure time (min) & 153.31 & 156.69 & 15.47 \\
Time to surgery (days) & 19.9 & & 0.309 \\
\hline
\end{tabular}

* denotes statistically significant differences between groups 
Table 2 Predictors of postoperative opioid dependence

\begin{tabular}{lll}
\hline Predictor & Odds ratio & $p$ value \\
\hline Fracture complexity & 1.93 & $0.049^{*}$ \\
ASA class 3 or 4 & 1.31 & 0.48 \\
Smoking status & 1.38 & 0.33 \\
Preoperative opioid dependence & 2.42 & $0.03^{*}$ \\
Obesity (BMI > 30) & 0.60 & 0.14 \\
Psychological comorbidity & 0.93 & 0.83 \\
Time to surgery > 30 days & 0.72 & 0.46 \\
\hline
\end{tabular}

* denotes statistically significant differences between groups

consistent with the orthopedic literature $[6,10,11,27]$. In addition, patients with preoperative opioid dependence had higher rates of opioid usage after fracture fixation [28, 29]. In orthopedic trauma, studies have found that patients with preoperative opioid use are associated with higher likelihood of prolonged postoperative opioid use and higher rates of doctor shopping [9]. Orthopedic surgeons must educate these patients prior to fracture fixation regarding their increased risks and support better oversite and weaning of these opioid medications postoperatively.

Another risk factor that was identified as an increased risk for opioid dependence was fracture complexity, with more complex fracture types there was nearly a doubled risk of opioid dependence. Pain associated with fractures in the upper extremity has been well documented, and previous literature has found that higher pain levels are associated with poorer clinical outcomes. Bone pain has been studied extensively in all fracture types, and research has shown that increased exposure of the periosteum and marrow cavity has been associated with increased pain sensation [16, 22]. In addition, previous studies have found that higher perceived pain levels are associated with catastrophizing and this may be a contributing factor to higher opioid use [30]. In this study, our results suggest the increased bone marrow exposure of more complex fractures is associated with higher opioid use which may be explained by higher perceived pain.

Surprisingly, there was no association between any demographic variable, except for a slightly higher risk of postoperative opioid dependence for smokers in this population. Considering that a traumatic injury such as a proximal humerus fracture is often the first interaction between an orthopedist and patient, understanding that all patients are susceptible to opioid abuse is important to screen appropriately. Surgeons can feel confident that the majority of trauma patients do not start on opioid-based medications until they suffer trauma, and other than preoperative use and fracture type there are no other demographic risk factors that surgeons should be screening for. Using the risk factors for opioid dependence identified through our study, future studies could develop risk calculators to help guide surgeons to optimize pain management postoperatively while mitigating risks of dependence.

While this study provides some important insights into the factors that influence postoperative opioid dependence after PHFs, it is not without limitations. Specifically, our opioid use data was collected from state-reported database and prescription data, the premise of our conclusions was based on the assumption that patients took their medications as prescribed. Although this may not always be the case, this is the most accurate method available to track opioid usage. In addition, while fractures were classified based on morphology, no examination of other injuries was included in this analysis which could have influenced opioid usage. In addition, we do not have any correlation to how opioid consumption affected outcomes following surgery. Finally, we only included surgically treated proximal humerus fractures, and the results cannot be extrapolated to non-operative or patients treated with an arthroplasty for their PHF. However, our goal was to focus our study with a specific PHF population to allow the most clear risk analysis of this population that could be utilized in future risk screening tools for surgical patients treated for a PHF.

\section{Conclusions}

Despite these limitations, some important conclusions can be drawn from our results. Primarily, it is clear that preoperatively narcotic-dependent patients with complex fractures are at a higher risk postoperative dependence, and if opioids are used, there needs to be an appropriate plan to limit amounts and support a gradual weaning off of these medications in the immediate postoperative period. Preoperative risk assessments including prior opioid use, fracture complexity, and smoking status may help surgeons recognize patients at increased risk for postoperative opioid dependence and support appropriate postoperative weaning plans from opioids. Future studies should focus on alternate non-opioid-based treatment plans for pain management following surgical treatment of PHF as well as how opioid dependence influences patient satisfaction and outcomes.

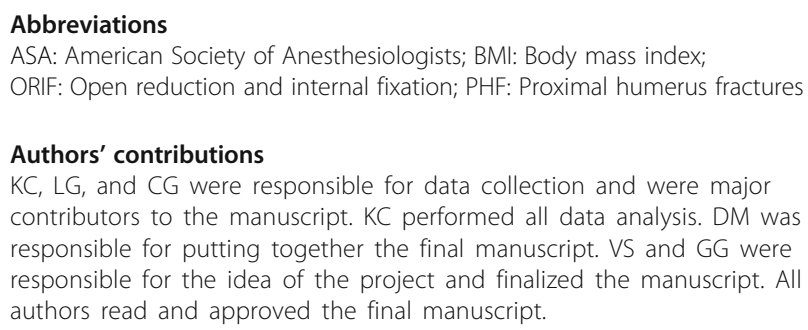

Funding

No funding was obtained for this study. 


\section{Availability of data and materials}

The datasets used and/or analyzed during the current study are available from the corresponding author on reasonable request.

\section{Ethics approval and consent to participate}

This was an IRB approved retrospective review, IRB approval number (FLA 17-022).

\section{Consent for publication}

Not applicable.

\section{Competing interests}

The authors declare that they have no competing interests.

\section{Publisher's Note}

Springer Nature remains neutral with regard to jurisdictional claims in published maps and institutional affiliations.

\section{Author details}

'Levitetz Department of Orthopedic Surgery, Cleveland Clinic Florida, 2950 Cleveland Clinic Blvd, Weston, FL 33132, USA. ${ }^{2}$ Charles E Schmidt School of Medicine, Florida Atlantic University, Boca Raton, USA.

Received: 4 March 2019 Accepted: 10 June 2019

Published online: 26 September 2019

\section{References}

1. Centers for Disease Control and Prevention. Opioid Overdoses. Opioid Data Analysis. https://www.cdc.gov/drugoverdose/data/analysis.html. Published 2018. Accessed July 26, 2018

2. Jiang $X$, Orton $M$, Feng $R$, et al. Chronic opioid usage in surgical patients in a large academic center. Ann Surg. 2016. https://doi.org/10.1097/SLA. 0000000000001780.

3. Holman JE, Stoddard GJ, Higgins TF. Rates of prescription opiate use before and after injury in patients with orthopaedic trauma and the risk factors for prolonged opiate use. J Bone Jt Surg - Ser A. 2013. https://doi.org/10.2106/ JBJS.L.00619.

4. Rosenbloom BN, McCartney CJL, Canzian S, Kreder HJ, Katz J. Predictors of prescription opioid use 4 months after traumatic musculoskeletal injury and corrective surgery: a prospective study. J Pain. 2017. https://doi.org/10.1016/ j.jpain.2017.03.006

5. Massey GM, Dodds HN, Roberts CS, Servoss TJ, Blondell RD. Toxicology screening in orthopedic trauma patients predicting duration of prescription opioid use. J Addict Dis. 2006. https://doi.org/10.1300/J069v24n04 03.

6. Vandenkerkhof EG, Hopman WM, Goldstein DH, et al. Impact of perioperative pain intensity, pain qualities, and opioid use on chronic pain after surgery: a prospective cohort study. Reg Anesth Pain Med. 2012. https://doi.org/10.1097/AAP.0b013e318237516e.

7. Lawrence JTR, London N, Bohlman HH, Chin KR. Preoperative narcotic use as a predictor of clinical outcome. Spine (Phila Pa 1976). 2008. https://doi. org/10.1097/BRS.0b013e3181809f07.

8. Hansen CA, Inacio MCS, Pratt NL, Roughead EE, Graves SE. Chronic use of opioids before and after Total knee arthroplasty: a retrospective cohort study. J Arthroplast. 2017. https://doi.org/10.1016/j.arth.2016.09.040.

9. Morris BJ, Sciascia AD, Jacobs CA, Edwards TB. Preoperative opioid use associated with worse outcomes after anatomic shoulder arthroplasty. J Shoulder Elb Surg. 2016. https://doi.org/10.1016/j.jse.2015.09.017.

10. Kim SC, Choudhry N, Franklin JM, et al. Patterns and predictors of persistent opioid use following hip or knee arthroplasty. Osteoarthr Cartil. 2017. https://doi.org/10.1016/j.joca.2017.04.002.

11. Rozell JC, Courtney PM, Dattilo JR, Wu CH, Lee GC. Preoperative opiate use independently predicts narcotic consumption and complications after total joint arthroplasty. J Arthroplast. 2017. https://doi.org/10.1016/j. arth.2017.04.002

12. Zywiel MG, Stroh DA, Lee SY, Bonutti PM, Mont MA. Chronic opioid use prior to total knee arthroplasty. J Bone Jt Surg - Ser A. 2011. https://doi.org/ 10.2106/JBJS.J.01473

13. Ben-Ari A, Chansky H, Rozet I. Preoperative opioid use is associated with early revision after Total knee arthroplasty: a study of male patients treated in the veterans affairs system. J Bone Joint Surg Am. 2017. https://doi.org/ 10.2106/JBJS.16.00167
14. Smith SR, Bido J, Collins JE, Yang H, Katz JN, Losina E. Impact of preoperative opioid use on Total knee arthroplasty outcomes. J Bone Jt Surg. 2017. https://doi.org/10.2106/JBJS.16.01200.

15. Summers S, Grau L, Massel D, Rosas S, Ong A, Hernandez VH. Opioid use disorders are associated with perioperative morbidity and mortality in the hip fracture population. J Orthop Trauma. 2018;32(5):238-44. https://doi.org/ 10.1097/BOT.0000000000001118.

16. Bot AGJ, Bekkers S, Arnstein PM, Smith RM, Ring D. Opioid use after fracture surgery correlates with pain intensity and satisfaction with pain relief. Clin Orthop Relat Res. 2014. https://doi.org/10.1007/s11999-014-3660-4.

17. Kaye AD, Jones MR, Kaye AM, et al. Prescription opioid abuse in chronic pain: an updated review of opioid abuse predictors and strategies to curb opioid abuse: part 1. Pain Physician Opioid Spec Issue. 2017;20:93-109 www.painphysicianjournal.com

18. Webster LR, Webster RM. Predicting aberrant behaviors in opioid-treated patients: preliminary validation of the opioid risk tool. Pain Med. 2005;6(6): 432-42. https://doi.org/10.1111/j.1526-4637.2005.00072.x

19. Vincent HK, Horodyski M, Vincent KR, Brisbane ST, Sadasivan KK. Psychological distress after orthopedic trauma: prevalence in patients and implications for rehabilitation. PM\&R. 2015. https://doi.org/10.1016/j.pmrj.2015.03.007.

20. Soderstrom CA, Dischinger PC, Gordon ; et al. Psychoactive Substance Dependence Among Trauma Center Patients $\mathrm{mmol} / \mathrm{L}$ ) adult trauma patients were evaluated for alcoholism and other PSUDs using the Structured Clinical Interview (SCI) from the Diagnostic and Statistical Manual of Mental Disorders, Revised Third Edition (DSM-III-R). Approximately half.

21. Rosenbloom BN, Khan S, Mccartney C, Katz J. Systematic review of persistent pain and psychological outcomes following traumatic musculoskeletal injury. J Pain Res. 2013:6-39. https://doi.org/10.2147/JPR.S38878.

22. Nencini S, Ivanusic JJ. The physiology of bone pain. How much do we really know? Front Physiol. 2016. https://doi.org/10.3389/fphys.2016.00157.

23. Carofino BC, Leopold SS. Classifications in brief: the neer classification for proximal humerus fractures. Clin Orthop Relat Res. 2013;471(1):39-43. https://doi.org/10.1007/s11999-012-2454-9.

24. Association AP. DSM 5; 2013. doi:https://doi.org/10.1176/appi.books. 9780890425596.744053

25. Electronic Florida online reporting of controlled substances evaluation.

26. State of Ohio Board of Pharmacy. Ohio automated Rx reporting system. https://www.ohiopmp.gov. Published 2017.

27. Aasvang E, Lunn T, Hansen T, Kristensen P, Solgaard S, Kehlet H. Chronic pre-operative opioid use and acute pain after fast-track total knee arthroplasty. Acta Anaesthesiol Scand. 2016.

28. Mohamadi A, Chan JJ, Lian J, et al. Risk factors and pooled rate of prolonged opioid use following trauma or surgery: a systematic review and meta-(regression) analysis. J Bone Joint Surg Am. 2018;100(15):1332-40. https://doi.org/10.2106/JBJS.17.01239.

29. Flanagan CD, Fuell Wysong E, Ramey JS, Gunasekar A, Vallier HA. Traumatic Orthopaedic injury is not an independent risk factor for high Postdischarge opioid consumption. J Am Acad Orthop Surg Glob Res Rev. 2017;1 (8):e058. https://doi.org/10.5435/JAAOSGlobal-D-17-00058.

30. Helmerhorst GTT, Vranceanu AM, Vrahas M, Smith M, Ring D. Risk factors for continued opioid use one to two months after surgery for musculoskeletal trauma. J Bone Jt Surg - Ser A. 2014. https://doi.org/10.2106/JBJS.L.01406.

Ready to submit your research? Choose BMC and benefit from

- fast, convenient online submission

- thorough peer review by experienced researchers in your field

- rapid publication on acceptance

- support for research data, including large and complex data types

- gold Open Access which fosters wider collaboration and increased citations

- maximum visibility for your research: over $100 \mathrm{M}$ website views per year

At BMC, research is always in progress.

Learn more biomedcentral.com/submissions 